\title{
The Construction of a Technicalization Model for Efficient Classroom Teaching
}

\author{
Xiaofeng Jiang and Dan Li
}

\begin{abstract}
This paper is aimed at striking a balance between efficient classroom teaching ideas and technology culture by constructing a technicalization model of efficient classroom teaching. Therefore, the paper first is made to analyze the common points enjoyed by both efficient classroom teaching and technology culture in different aspects. Advanced teaching reform ideas can be put into practice through technology thoughts, technology means and technology process. In other words, it is necessary to achieve the accurate teaching reform ideas via technology thoughts, modern teaching means by technology means and processed teaching through technology process. This paper focuses on the analysis of technologizing process of efficient classroom teaching, which requires that we raise the efficiency of classroom teaching with the help of technology culture and combine macroscopic "technological design" with microscopic "artistic innovation", so as to strike a balance between both aspects. In other words, it is aimed at realizing a balance between visible model and invisible reform, thoughts innovation and technology cooperation as well as learning environment and teaching control.
\end{abstract}

Index Terms-Efficient classroom teaching, technicalization model, construction.

\section{INTRODUCTION}

Dozens of years has passed since China launched the classroom teaching reform. With the reform going into depth, great changes have taken place in classroom teaching. Class is supposed to be the main front of teaching. The fundamental nature of teaching reform is the reform of class. How can we give an efficient class? Everyone is thinking hard on this question and making research. We can say that the classroom teaching reform directed by the thought of emancipating students and high efficiency, with autonomy, cooperation and research as its core, is carried out in its full swing. Some significant changes take place on class, which deserves satisfaction of all the teaching staff. However, we admit all kinds of hard issues arising on this new kind of class during its development.

Efficient classroom teaching is the extension and upgrade of "effective teaching" [1], which is committed to increasing the efficiency, effectiveness and benefit of classroom teaching.

Manuscript received April 9, 2016; revised August 30, 2016. This work is supported by the Twelfth five-year Research Project of Hunan Office for Education Sciences Planning of China: Research on the Mode of Multi-dimensional Interaction Teaching in Higher Vocational Colleges in Hunan (No. XJK014CZY050).

Xaiofeng Jiang is with Research Department of Hunan Golf and Tourism College, Changde, Hunan, China (e-mail: 494683897@qq.com).

Dan $\mathrm{Li}$ is with School of Railway Operation and Management, Hunan Railway Professional Technology College, Hunan, China (e-mail: womaggielee@hotmail.com).
The teaching reform ideas must be carried out with the help of technology, as the perfect combination of ideas and technology holds the key to the construction of modern classroom teaching. They also serve the two main points in pushing forward the reform. With the reform going into depth, flip classroom, Cloud classroom and MOOCS all become part of the reform practice, which brings out the model of "Three, Four, Five and Six", "Starbucks-style Classroom" and some other new efficient models. "the efficient classroom teaching is featured by art and technology" [2]. Efficient classroom teaching is an art in that its application boasts variations and opportunities. Meanwhile, it is also a technology because there are still rules and routines to follow in its application. Therefore, one of the inner routes of reform is to seek a perfect combination between ideas of efficient class teaching and technology culture.

The application of technology into efficient classroom teaching is conducted in an all-round way, which combines technology culture and advanced teaching reform ideas closely. Therefore, this paper is aimed at constructing technicalization model of efficient classroom teaching, realizing perfect match between advanced ideas and technology and providing a new perspective of pushing forward the reform.

\section{THE INNER CONNECTION BETWEEN EFFICIENT Classroom Teaching AND TeChNOLOGY Culture}

Different people hold different views on technology. Taken together, technology is a kind of culture and a complex organism consisting of thoughts and tools. It is a complicated integration which involves values, knowledge and methods of applying. Value leads the application of technology; knowledge represents the subjective creative power of technology, while methods are the physical realization media of technology. The junctions of the ideas of efficient classroom can be found at all levels of technology culture.

\section{A. The Interdependent Relationship between Efficient Classroom Teaching and Technology Means}

Looking from the practice of classroom teaching reform, various specific teaching ideas have been introduced, such as multi-interaction, TLLM and self-leading learning, which become the basis of efficient classroom teaching form. The integration of advanced ideas and technology means has spurred many reform supporters to put up with a lot of new class technical methods, therefore providing material foundation for the soft landing of efficient class teaching. For example, the three useful tools for study raised by Li Bingting: spring-binder, two-color pencil and error correction notebook, 
one document and three leaflets.(study plan, problems leaflet and problems training leaflet).All these technical methods play an effective role in raising students learning efficiency. Obviously, an interdependent relationship could be found between efficient classroom and technology means and process: with the application of the advanced ideas, the powerful practice function of the tools and modes to increase the classroom effectiveness is highlighted; with the help of technology means, the great potential of efficient classroom ideas reforming the practice is unleashed.

\section{B. Efficient Classroom Teaching Practice is under Control with the Help of Technology Thoughts}

Though for teachers, the practice of efficient classroom is a process of improving, elaborating and coping wisely, from the view point of technology, teachers can control the process of efficient classroom practice with the help of technology thoughts. The technology thoughts refer to the stable way of thinking and fixed practice modes hidden behind all the technologized conducts and phenomenon. Its core characteristics are controllability, technologizing, certainty and transferability. The changeful class art, teaching strategies and teaching reform experience should be improved to be stable class technology. To change the invisible teaching thoughts into visible teaching reform experience and action diagram is what the technical thoughts of efficient classroom teaching is all about. At present, the domestic popular "271 Class Rules" and "Three-Three-Six Self-Study Mode" both follow the technical thinking of "learning before guiding" and "TLLM," "Take the Khan Academy for example. It follows the technology thoughts of 'students dominant' and the 'switch of teaching and learning"' [3].

\section{Indispensable Demand of Information Technology Knowledge from the Efficient Classroom's Part}

Teaching informationization is the focus of efficient classroom. Information technology knowledge is the basic literacy an efficient classroom practitioner should be equipped with. Nowadays, a lot of information technology means (such as Wiki, Blog, cloud computation and so on) have emerged and change the forms and settings of efficient classroom to a great extent.

With the support of information technology, micro video has been extensively applied in class; IMOOC has been promoted worldwide; distance network teaching has been a usual practice and flip classroom has become the typical representative of new efficient classroom. "Contemporary classroom teaching must be added with information technology because it has become an indispensable tool in contemporary teaching [4]," The insight makes sense. It is because of the help of micro video technology that the "students dominant" and the "switch" of the teaching process and the relation between teachers and students can be possibly realized in efficient classroom.

\section{The CONSTRUCTION OF EFFICIENT ClASSROOM TECHNOLOGIZING MODEL}

It is impossible to duplicate, reproduce and testify in the efficient classroom. But subtly combined with modern technology, the variable classroom arts, teaching strategies and teaching reform experience can be generalized into relatively stable classroom technologies. Thus the abstract teaching wisdoms can be transformed into the experience of classroom reform. Demonstrated by technology thoughts and means, the reform brought by the advanced teaching ideas is the goal and mission of efficient classroom technologizing, based on which the efficient classroom technologizing model is built as below, see Fig. 1 .

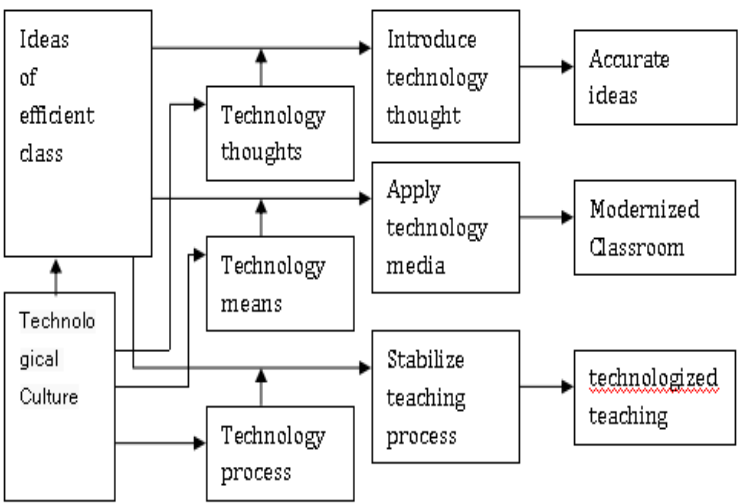

Fig. 1. A technicalization model in efficient classroom teaching.

As it is demonstrated by Fig. 1, the technologizing process process of efficient classroom is in fact the technologizing application process of efficient classroom ideas. It is the process of improving the efficiency of classroom teaching with the help of technology culture. In the process, the three elements of technology culture (technology thoughts, technology means and technology process) are combined with introducing technology thoughts, applying technology media and stabilizing teaching process respectively to achieve the goals of accurate ideas, modernized classroom and technologized teaching. With the help of the above mentioned classroom technologies, efficient classroom ideas are turned into concrete, visible and applicable effective classroom form.

\section{A. The Precision of Teaching Reform Ideas: The Teaching Reform Ideas Should Be Made Definite with the Help of Technology Thoughts}

The top meaning of efficient classroom technologizing is to make advanced ideas regarding effective classroom teaching clear and definite with the help of technical thoughts, making it the guideline of optimizing class practice followed by most teachers. The details are list as follows: to give a precise definition of effective class; to refine and define the concrete meaning of effective class in line with certain optimization process; to make evaluation on science of effective classroom teaching ideas and so on. Take the concept of "TLLM" as the example. We can detail its meaning as the switch of position between students and teachers. In other words, it suggests that teachers become an assistant to students and students remain dominant on class; the teaching contents can be classified into teaching content and learning content; to refine the assignment of teaching for both sides; "to diversify the ways of learning and extend the proportion of self-study, group-study and combined learning" [5]; to reduce the work of class teaching by teachers; to identify some extreme ideas about teaching as non-TLLM 
thoughts(for say, teachers almost not meddle with students' study at all on class) So, we can make the concrete meaning of effective classroom much more clear, detailed and definite with the help of technology; reduce misunderstanding and proportion of inexplicit teaching reform ideas. In this way, the class teaching reform is able to win much more support.

\section{B. The Modernized Teaching Methods: To Give Teaching} Technical Support under the Help of Technical Media

The precision of effective class teaching is only the first step leading to its technicalization. We are able to change the class teaching into a modernized one by rebuilding the learning environment and changing the way of students learning with the help of various modern technology means. A variety of modern media can be applied to efficient classroom teaching. In this era of information, the use of a lot of modern media on class has initiated second revolution in teaching reform. And this phenomenon is featured by wide development of some courses, such as micro-video course, MOOCS, open- course channels, video-sharing course and so on. All these class forms are actually the product of the integration of teaching contents and modern information technology. Under the help of Cloud technology, large amounts of video-courses can be shared on Cloud and "Class in Air", making it closely associated with the idea of personalized learning. Thanks to the development of excellent video-course, the distinguished teachers at home and even from other parts of the world as well as valuable courses have been introduced into thousands of ordinary households, making quality teaching possible. With the combination of advanced ideas about teaching reform and modern technology, much more progress is to be made. Therefore, "applying information to efficient classroom teaching is not only a win-win cooperation between ideas and technology but also a high-end collaboration between education and technology" [6]. Such a practice is sure to have great effect on the further development of mankind.

\section{The Technologizing of Teaching Process: Elaborate Designed Process Contributes to Fixed Pattern of Teaching Process}

Technology not only refers to means and thinking, but also a kind of process and operation. It is able to offer us a way to the ideal results which is the most optimized and scientific. That is the nature of technology when it is considered as a new process. The support of ideas and technology doesn't necessarily lead to an effective teaching class. Therefore, it is suggested that we apply these methods and thoughts in an organized way to our teaching process. The last step to the technologizing process of efficient classroom is to apply related technology in a scientific way to teaching process under the guide of teaching reform ideas. "A classic typical of effective class teaching mode is flip classroom, which enjoys an integration of modern information technology, effective classroom ideas and teaching process" [7]. On a flip classroom, teachers construct a new learning process focusing on "internalization" with the help of a series of technology (micro-video course, network community, online-study, and distance learning interaction) It refers to question-guide, then video-watching and question-solving at last. Flip classroom adopts teaching technique that is based on modern information technology and contemporary teaching theories. The supreme goal of effective classroom teaching is to form a fixed teaching structure and process with the help of procedural technology.

We can see that with the technology culture adopted into the effective classroom teaching in an all-round way, the class will take on a new look: the advanced teaching ideas will be expressed in a clear way during the teaching process; the interaction between students and teachers on information, experience and emotion will be greatly supported by large amounts of technical media; blended-learning, micro-video, mobile-learning and E-learning will become a necessary part of class teaching; each teaching design, application and evaluation will be conducted on the basis of standard process. The technologicalization of efficient classroom teaching will overcome such disadvantages as misunderstanding of effective class ideas, poor media resources and stereotype process design, thus providing solid foundation both technologically and culturally in realizing modern and scientific effective classroom teaching.

\section{The TeChnologizing PATH to EFFicient ClassRoom TEACHING}

Increasing the technology content and art proportion of reform is the two important practical path to co-construct the reform of efficient class. The technologizing path of efficient class is not just pushing the "technology supremacism", "technology-oriented" or "technology worship" but the combination of macroscopically "technological design" and microscopically "artistic creation" and to strike a balance between the technological and artistic property.

\section{A. The Balance between the Concrete Modes and Abstract Reform}

What efficient classroom technology pursues are the concrete means, process and modes. They are physicalized forms of classroom ideas. Therefore, without the concrete technology means, process and media, it is hard for efficient classroom technology to exist. But the concrete technology media are both the advantages and disadvantages of efficient classroom technology.

For one hand, the fixed technology process and media provide strong material support for efficient classroom, put the classroom plan into practice and pave the way for the practice of good ideas to equip ordinary teachers with technology process and practice essentials with a little training and achieve the ideal efficiency. On the other hand, the most highlighted feature of classroom technology is stabilizing certain teaching steps and processes (such as stabilized examples, stabilized modes and stabilized means). Therefore, the flexibility of teachers in classroom teaching may be compromised. The space for teachers' innovations and reforms may be limited, which is not good for the handling of unusual and unexpected incidents. So "the balance between the concrete modes and abstract reform should be paid attention to in the technologizing reform of efficient classroom, which is the guarantee of teachers' freedom in class" [8]. 


\section{B. The Balance between the Idea Innovation and Technology Support}

During the process of efficient classroom technologizing, good advanced ideas are the foundation of classroom technologizing and the supporting point of booting smooth classroom reform. Without the strong support of advanced ideas, the reform of efficient classroom could possibly be in the danger of "superficial foundation," So the strengths and weaknesses of all technologizing forms of efficient classroom should be clear found out to constantly reflect on the defects and misunderstandings of class reform ideas in the practice and to strife for an inter-prompted and dynamic balanced regurgitating relation between the two. A good idea could trigger a series of advanced classroom technologies. Technology thoughts, means and process are only the servants to realize these ideas. But it should be also pointed out that without good technologies, the potential of good ideas cannot be fully unleashed in teaching practice. Based on the above analysis, idea innovation is equally important to technology support in the efficient classroom practice. Promoting the classroom technology development and class reform idea innovation in balance constantly is the only right way to efficient classroom reform.

\section{The Balance between Learning Environment and Teaching Control}

"To teach means to let people learn" [9], the students' learning is irreplaceable. In classroom teaching, "one of the core objective of applying technology means is to try the best to create an atmosphere under which students are willing to learn and able to learn proactively and to make the learning process more free, self-motivated and proactive" [10]. On one hand, teachers should fully utilize the advantages and functions of technology means to take advantage of all kinds of audial and visual equipment, on-line communication channels, rich course resources to create an environment to encourage students' self-study. For example, let students preview learning micro video courses to trigger questions and participate in class discussions; let students participate in model community discussion and guide the parents to join and take advantages of other social educators to establish a platform for self-learning. On the other hand, teachers should be good at control the timing of teaching control. In teaching, after the students' passion for self-learning is triggered, all kinds of things could happen in teaching activities which might be in the misunderstanding and dead end anytime. At this time, the teachers' teaching control (such as to lead, to guide, to encourage and to enhance) is especially important. For example, in model community discussion, teachers should be deeply involved in students' discussion as experts or teachers to control the topic. In the in-class discussion of flip class, teachers should be good at monitoring the talks, guiding the direction and control the excitement of the discussion. Therefore, the creation of self-learning environment is equally important to teaching control in the process of efficient classroom technologizing.

\section{CONCLUSION}

Obviously, ideas and technology are two key points in pushing forward the class teaching reform. The reform of efficient classroom cannot be carried out without the support of modern technology culture. But the technologizing of efficient classroom is not formatting, prefabricating and lining all classroom teaching activities but provides enough space for innovations of teachers and students in details and parts. The technicalization model of efficient classroom teaching in this paper is just a tentative exploration of the further teaching reform, which is targeted at offering a new perspective for the reform. How can we apply the modern media in a better way for the class teaching form innovation? How can we get advanced teaching process fixed in a more efficient way? All of questions like this demand our deep and further study. Furthermore, analyzing from the technical culture perspective, to explain both advantages and disadvantages of typical cases of effective class in a clearer way is our research direction and focus in the next step.

\section{REFERENCES}

[1] L. Baoxin and Z. Lichang, "The idea and action of efficient classroom (in Chinese)," Xian Shanxi Normal University Press, 2014, p. 2.

[2] Li Bingting, "The art and technology on effective classroom," Elementary and Middle School Administration, vol. 1, 2010, pp. 43-45.

[3] W. Hong, Z. Wei, and S. Lihong, "The design of flip class teaching model - Based on the analysis of domestic and abroad typical cases (in Chinese)," Modern Education Technology, vol. 8, 2013, pp. 5-10.

[4] Y. Lan, "Recognition of classroom teaching process: Focus on comment on abroad (in Chinese)," Course Materials Teaching, vol. 5, 2013, pp. 3-13.

[5] W.-H. Li, "The construction of effective history class Teaching mode," Education and Teaching Forum, vol. 36, 2014, pp. 59-60.

[6] Z. Lichang, "Analysis on the technology and its connotation of efficient classroom (in Chinese)," Hunan Normal University Education Science, vol. 3, 2014, pp. 46-49.

[7] X.-L. Zhao, "The Internalization Process and Teaching Design on Flip Classroom," Modern Distance Education Research, vol. 2, 2014, pp. 55-61.

[8] B.-X. Long and F. Sun, "On intrinsic relation and balance point of technicalization model in efficient class," Modern Distance Education Research, vol. 6, 2014, pp. 34-40.

[9] Z. Huang, "Conversation with teaching: Connotation and value (in Chinese)," Global Education, vol. 6, 2008, pp. 7-16.

[10] B. Zhou, "The outline of class phenomenology - On the choice of class teaching study," Education Study, vol. 5, 2012, pp. 95-101.

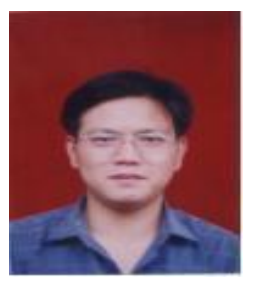

Xiaofeng Jiang was born in Hunan, China, in 1977. He graduated with a BA degree in Chinese linguistic literature from Hunan Normal University, Hunan, China, in 2003. He got his MA degree in educational economy and management from Hunan Normal University, Hunan China, in 2007.

$\mathrm{He}$ is currently working in Hunan Golf and Tourism College, an associate Professor and the director of the Research Department. His representive publications are "A study on China's education policies in the last two decades," Journal of the Chinese Society of Education, 2007, etc. His areas of interest are teaching, higher vocational education and modern educational technique. 